\title{
InVestigating Hotel OUtsourcing in the EgyPTian Hotel Market: REASONS, BARRIERS AND ACTIVITIES
}

\author{
Sayed S. El-Houshy \\ Demonstrator, Hotels Studies Department \\ Faculty of Tourism \& Hotels, Alexandria University
}

\author{
Jailan M. El-Dmerdash \\ Associate Professor, Hotels Studies Department \\ Faculty of Tourism \& Hotels, Alexandria University
}

\author{
Osman A. El-Said \\ Lecturer, Hotels Studies Department \\ Faculty of Tourism \& Hotels, Alexandria University
}

\begin{abstract}
Due to the increasing importance of "Outsourcing" as one of the strategic management tools used by hotels worldwide, the current study attempts to assess hotel outsourcing in the Egyptian Hotel Industry by providing insights into the outsourcing drivers or reasons and the encountered barriers. The study also discusses the most common activities outsourced by hotels in Cairo and Sharm El Sheikh.

A total of 48 participants including General and Department Managers working in four and five-star hotels, mainly in Cairo and Sharm El Sheikh participated in this study. The methods used to collect data included personal interviews using a structured questionnaire.

The findings revealed that outsourcing occurs in a variety of hotel functions and departments including information technology, transportation services, health club, pest control, animation, security, reservation, as well as other activities. The main reasons for outsourcing in hotels were found to be access of external expertise, reducing costs and focusing on core activities. Although participating hotels showed interest to expand their scope of outsourcing some constraints are limiting their ability to do so. Lack of reliable suppliers, minimal knowledge concerning outsourcing adoption, possible risk of providing unqualified staff and hidden relevant costs represented the most significant barriers of outsourcing.

Finally, the study presents a group of practical and academic recommendations.
\end{abstract}

Keywords: Outsourcing; Cairo and Sharm El Sheikh hotels; outsourcing reasons, barriers and functions.

\section{Introduction}

In today's hospitality market of rapid change, social, political, and economic volatility, globalization trends and technological advances, customers' increasing demands and fiercer competition, hotels world-wide are engaging in a range of creative strategies in an effort to remain competitive, and accomplish long-term growth (Glagola, 2000; Heywood, 
2001; Espino-Rodriguez \& Gil-Padilla, 2005; Merrifield, 2006; Burgess, 2007; Lee, 2008; McIvor, 2009; Wan \& Su, 2010). One of these widely recommended strategies that provides significant advantages for both cost reduction and quality improvement is "outsourcing" (Maiga \& Jacobs, 2004; Lam \& Han, 2005; Lamminmaki, 2007; Potkány, 2008; Bolat \& Yilmaz, 2009; Baytok et al., 2013; Hiamey \& Amenumey, 2013; Promsivapallop et al., 2015).

Outsourcing is a management strategy in which a hotel utilizes a specialized supplier, forming strategic alliances with it to have the supplier operates certain hotel functions, in an attempt to reduce costs and risks and improve efficiency. This strategy allows hotels to focus efforts on core competencies and strengthen their ability to adapt in the everchanging business environment, without having to invest in people and technology ((Lam \& Han, 2005; Lau \& Zhang, 2006). By embarking into outsourcing, firms can offer better client service, produce a better product, and do a better job efficiently (Hamzah et al., 2010).

The use of outsourcing has grown exponentially in recent years with predictions for continued growth. Hospitality enterprises, which include a variety of activities and where customer satisfaction is the main determinant of success and whose sales fluctuate seasonally, weekly and daily, are suitable for the utilization of outsourcing in terms of nature of their structure and operations (Lamminmaki, 2008; Gonzales et al., 2011; Lamminmaki, 2011; Yildiz \& Demirel, 2014). Hotels can use outsourcing in different departments (Yildiz \& Demirel, 2014). Some of the activities or processes that hotels might outsource are the ones related to laundry, security and surveillance, leisure activities, gardening services, training, information systems and cleaning (EspinoRodriguez \& N-Robaina, 2005), animation and public relations (Bolat \&Yilmaz, 2009), transport services, recruitment and head hunting (Hiamey \& Amenumey, 2013), concierge, restaurants, gift shops, business centers, IT , and much more (Smith, 2012).

The literature has been rich in studying outsourcing and its implementation in the hotel sector. Recent years have seen increased attention given to hotel outsourcing where significant parts of hotel operations and management have been outsourced and documented in some parts of the world; mainly Europe, North America and Asia (Hemmington \& King, 2000; Paraskevas \& Buhalis, 2002; Espino- Rodriguez \& PadronRobaina, 2004; Espino-Rodriguez \& Gil-Padilla, 2005a, b; Lam \& Han, 2005; Lamminmaki, 2005, 2008; Donada \& Nogatchewsky, 2009). Furthermore, there has been attention directed to hotel outsourcing in professional-oriented periodicals and greater interest shown by hospitality researchers (Hemmington \& King, 2000; Espino-Rodriguez \& Padron-Robaina, 2004, 2005; Lam \& Han, 2005; Lamminmaki, 2003, 2005, 2007; Potkány, 2008; Bolat \& Yilmaz, 2009; Baytok et al., 2013; Hiamey \& Amenumey, 2013). However, the consulted literature revealed limited research interest towards outsourcing in the Egyptian hotel industry. This lack of research interest is surprising, as outsourcing has become a significant facet of modern hotel management (Rowe, 1994; Hottman \& Adams, 1996). Therefore studying hotel outsourcing is one of the significant fields that should be investigated in context of the Egyptian hotel market. Although hotels in Egypt may be engaged in one form of outsourcing or the other, little is known of what actually happens in these hotels. Therefore, this study sets out with the aim of investigating the current status of outsourcing by determining the most common activities outsourced by hotels as well as the reasons for outsourcing and its anticipated barriers. 
Thus, the problem of the study can be stated in the following question: "'What are the activities currently outsourced by hotels in Egypt? What are their reasons for outsourcing and the barriers faced by these hotels?

By answering this question, the study will be able to achieve a number of objectives:

- Examining the types of services and functions that are currently outsourced by hotels

- Determining the reasons for using outsourcing in hotels bearing in mind three main dimensions: core competency, expertise search and cost reduction

- Identifying the barriers that would be facing hotel managers when adopting outsourcing and thus preventing them from applying it

- Providing a further insight for academics and hotel managers on the concept of "outsourcing" and how it can enhance the competitiveness of the hotel industry

- Finally, portraying the future of outsourcing in the hotel industry and the essence of applying this concept as a strategic management tool

\section{Review of Literature}

Defining Outsourcing. Outsourcing is simply made up of two words "out" referring to exterior and "source" referring to origin or resource, which, in business terms means that certain activities are obtained outside the firm (Espino-Rodriguez \& Gil-Padilla, 2005). Outsourcing is the process of transferring an internal activity to an external body and it involves at least two parties: client and outsourcer (Galahitiyawe \& Musa, 2011). The organization transferring this work is referred to as the client (i.e. hotel) and the organization that conducts the work and makes decisions is the outsourcer or the service provider (Power et al., 2006).

Different studies have developed different definitions for outsourcing (Galahitiyawe \& Musa, 2011; Nayebzadeh et al., 2013). However, almost all the reviewed literature refereed to the definition as a problematic aspect that needs to be investigated in order to understand what the concept actually means and how it is applied. Therefore, a summary of different definitions and views of outsourcing is presented in Table 1 .

Table 1: Summary of the Previous Definitions of Outsourcing

\begin{tabular}{|l|l|}
\hline Authors & Definitions \\
\hline $\begin{array}{l}\text { Loh and Venkatraman } \\
(1992)\end{array}$ & Described outsourcing as "Contribution by external vendors" (p. 9). \\
\hline Elfing and Baven (1994) & $\begin{array}{l}\text { Outsourcing is a form of predetermined external provision with another enterprise } \\
\text { for the delivery of goods and/or services } \\
\text { in-house. }\end{array}$ \\
\hline Campbell (1995) & $\begin{array}{l}\text { Outsourcing is } \text { a managed process } \text { of transferring activities to be performed by } \\
\text { others. }\end{array}$ \\
\hline Domberger (1998) & $\begin{array}{l}\text { Outsourcing is sourcing activities that } \text { a firm has internal capability to conduct } \text { or } \\
\text { carry out internally. }\end{array}$ \\
\hline $\begin{array}{l}\text { Kakabadse and } \\
\text { Kakabadse, (2000) }\end{array}$ & $\begin{array}{l}\text { Outsourcing is described as a business's external provision of the services and } \\
\text { activities, } \text { relying on a contract, } \text {, that were previously offered by using the sources } \\
\text { in-house. }\end{array}$ \\
\hline $\begin{array}{l}\text { Zhu, Hsu, and Lillie, } \\
\text { (2001) }\end{array}$ & $\begin{array}{l}\text { "Outsourcing is the process of transferring the responsibility for a specific } \\
\text { business function from an employee group to a non-employee group" (p. 374). }\end{array}$ \\
\hline
\end{tabular}




\begin{tabular}{|c|c|}
\hline Heywood (2001) & $\begin{array}{l}\text { "Outsourcing is the transferring of an internal business function or functions, } \\
\text { plus any associated assets, to an external supplier or service provider who offers } \\
\text { a defined service for a specified period of time, at an agreed but probably } \\
\text { qualified price" (p. 25). }\end{array}$ \\
\hline $\begin{array}{l}\text { Kern and Willcocks } \\
(2002)\end{array}$ & Outsourcing is the contracting out of any service or activity to a third party. \\
\hline Barthélemy (2003) & $\begin{array}{l}\text { Outsourcing is "Turning over all or part of an organizational activity to an } \\
\text { outside vendor" (p.93). }\end{array}$ \\
\hline $\begin{array}{l}\text { Ecerkale and Kovanc1 } \\
(2005)\end{array}$ & $\begin{array}{l}\text { "Outsourcing is that an enterprise offers a service through another company } \\
\text { specialized in the service-related matter instead of producing such service within } \\
\text { its own body" (p. 70). }\end{array}$ \\
\hline $\begin{array}{l}\text { Grossman and Helpman } \\
(2005)\end{array}$ & $\begin{array}{l}\text { Outsourcing means "finding a partner with which a firm can establish a bilateral } \\
\text { relationship and having the partner undertakes relationship-specific investments } \\
\text { so that it becomes able to produce goods or services that fit the firm's particular } \\
\text { needs. Often, but not always, the bilateral relationship is governed by a contract" } \\
\text { (p. 136). }\end{array}$ \\
\hline Lam and Han (2005) & $\begin{array}{l}\text { "Outsourcing is a management strategy in which a hotel utilizes a specialized } \\
\text { outsourcing supplier, forming strategic alliances with it to have the supplier } \\
\text { operate certain hotel functions, in an attempt to reduce costs and risks and } \\
\text { improve efficiency" (p. 43). }\end{array}$ \\
\hline $\begin{array}{l}\text { Espino-Rodriguez and } \\
\text { Padron-Robaina (2006) }\end{array}$ & $\begin{array}{l}\text { "Outsourcing is a strategic decision that entails the external contracting of } \\
\text { determined nonstrategic activities or business processes necessary for the } \\
\text { manufacture of goods or the provision of services by means of agreements or } \\
\text { contracts with higher capability firms to undertake those activities or business } \\
\text { processes, with the aim of improving competitive advantage" (p. 52). }\end{array}$ \\
\hline Kancharlan (2007) & $\begin{array}{l}\text { Outsourcing can be defined in simple terms to describe a situation where one } \\
\text { organization gives work to other firms, which can execute this work more } \\
\text { efficiently, usually for lower costs, and whose capabilities complement or } \\
\text { supplement their own. }\end{array}$ \\
\hline $\begin{array}{l}\text { Sani, Dezdar, and Ainin } \\
(2013)\end{array}$ & $\begin{array}{l}\text { Outsourcing is defined as a subcontracting service or a third party for strategic } \\
\text { use of firm's resources, to generate firm's values and grow competitive edge. }\end{array}$ \\
\hline
\end{tabular}

\section{Source: The researchers built on the literature reviewed}

Built on the above, this study attempts to define hotel outsourcing as "an arrangement whereby a hotel depends on an outside entity to perform its activities in an attempt to access external expertise, focus on core activities, and/or reduce costs". Thus, the current study considers two main criteria that should exist in any outsourcing transaction, and the hotel activity is outsourced when it meets these two criteria; the activity is undertaken by external entity or vendor and it is traditionally offered or can be offered in-house

Reasons of Hotel Outsourcing. There are many reasons for outsourcing practices in hospitality enterprises. This can include gaining competitive advantage, increasing service quality, reducing costs, focusing on core competencies, providing added value, accessing technology, skills, knowledge and human resources which are not available internally, in addition to obtaining better service from suppliers (Espino-Rodriguez \& Padrón Robaina, 2005; Espino-Rodriguez \& Gil-Padilla, 2005; Wan \& Su, 2010; Gonzales et al., 2011). These reasons can be grouped under three main headings; focusing on core activities/competencies; lack of internal capabilities/expertise search; and reducing costs

Focusing on Core Competencies. To focus on core competencies many organizations make a decision to outsource some of their activities (Cooper, 2007; Potkány, 2008; Sriwongwanna, 2009). The term 'core' means key, critical or fundamental, and 
"competence" is the capability, skill, or ability. Quinn and Himler (1994), regarded core competencies as activities that the firm is continuously engaged in, whilst non-core activities are peripheral to a company's competitive advantage. Ordoobadi (2009) also indicated that core competencies distinguish a company from its competitors; they are activities that offer long-term competitive advantage and must be invested in, controlled, and protected. In simple terms, core competencies refer to the group of activities that are critical to the hotel success.

Core areas in the hospitality industry are areas that lead to direct interface with guest and usually requiring great service skills, i.e., check-in and checkout and room service (Harrison \& Enz, 2005; Wan \& Su, 2010). These areas are difficult to outsource due to the need to maintain direct oversight responsibility (Hiamey \& Amenumey, 2013). By focusing on core activities, hotels will lavishly enjoy the benefits while maintaining their core business and outsource their non-core business to the right third party (Lamminmaki, 2003). In addition, hotels will receive a good feedback on their organizational aims, be able to improve business performance, ability to keep on track on the budget and reduce cost and ability to generate maximum profit and revenue (Ghodeswar \& Vaidyanathan, 2008). For instance, outsourcing human resource (HR) activities can reduce the workload of existing HR staff, thereby allowing the organization to primarily focus on strategic decisions making and developing core competencies (Hansen, 2009).

In determining which activities should be outsourced, it is widely suggested that core activities should be insourced and non-core activities outsourced. Many researchers do not encourage the outsourcing of core competencies, as contracting the provision of key parts and components can lose an organization its core competence, or the opportunity to create one (Domberger, 1998; Kakabadse \& Kakabadse, 2000; Lamminmaki, 2003). In context of hotels, there is a great tendency to consider that the sales, reception, and administration are core activities (Rodriguez \& Robaina, 2005). Understanding and serving the customer is also be regarded by organizations as a core competency (Quinn \& Hilmer, 1994). In their study Bolat and Yilmaz (2009), examined empirically the influence of outsourcing of non-core hotel activities upon hotel's performance, found that hotel performance improved when hotels focus on their core competencies, and outsource non-core activities.

Lack of Internal Capabilities. Another reason for venturing into outsourcing is the acquisition of technical skills, knowledge and products or services that are lacking internally (Wan \& Su, 2010; Hiamey \& Amenumey, 2013). Outsourcing gives access to talents that are not available in-house (Embleton \& Wright, 1998). According to Rodrigues et al. (2008), the decision of outsourcing or insourcing a hotel activity is linked to a firm's available knowledge and skill related to this particular activity. For example, a hotel may outsource the staff training function, if it does not have the required expertise to manage internally. In the same vein, outsourcing gives access to resources and services that are not available in-house and enables firms to overcome the limited amount of resources available internally. For example, a hotel may not be able to provide its own laundry service due to its building's design (Lamminmaki, 2005).

Wan and Su (2010); Hiamey and Amenumey (2013) found that, most hotels need technical skills and competencies from outside, as they do not have the personnel with such skills to perform certain functions. Those functions such as; lift and power plants maintenance and central air conditioning retrofitting. Suppliers provide the firm with resources in which they are specialized and have invested over time in order to develop 
their operations. Thus, their capability is higher than any firm that develops the operation in-house. That potential for competitive advantage may be transmitted to firms that acquire the service, in that there will be lower costs, higher professionalism and higher quality in the services that have been outsourced (Quinn, 1999; Rodrigues et al., 2008).

Cost Reduction. Cost reduction is one of the main reasons for venturing into outsourcing (Corbett, 2004; Donada \& Nogatchewsky, 2009; McIvor, 2009). Previous studies provided extensive commentary concerned with outsourcing induced cost savings. For instance, Domberger et al. (1994) stated that, organizations that outsource services are able to cut costs by about $20 \%$ without affecting service quality. Stroh and Treehuboff (2003) claimed that outsourcing is seen as a cost saving strategy. The term cost savings is referred to as lower costs compared to the in-house production (Sani et al., 2013). To justify outsourcing managers always compare the cost of carrying out a function in-house and the cost of getting the service or activity from outside contractors (Kremic et al., 2006). For example, the cost of setting up a plant, its maintenance, and the training of its personnel were the reasons why hotels outsourced its laundry services (Hiamey \& Amenumey, 2013). The same can be said for those hotels, which has outsourced its transport services because of the cost of purchasing vehicles, maintaining them and paying the drivers (Hiamey \& Amenumey, 2013).

Many researchers (Espino-Rodriguez \& Padron-Robaina, 2005; Lam \& Han, 2005; Dorasamy et al., 2010; Lamminmaki, 2003; 2011; Hiamey \& Amenumey 2013), identified cost reduction as one of the most important motivations for outsourcing. In the study conducted by Hiamey and Amenumey (2013), reduction of labor cost has been one of the main concerns of all the hotel managers who did not want to assume additional cost by directly employing people. Soltani and Wilkinson (2010) have also noted outsourcing as a means of minimizing labor costs in the hospitality industry. Lamminmaki (2011) indicated that cost savings could be achieved significantly by outsourcing without leading to lower quality. Because functions performed by the outside suppliers represent their core competences, those suppliers are more likely to be able to provide the products or services at a lower cost and higher quality than the firms could (Espino- Rodriguez \& Padron-Robaina, 2004).

Challenges and Barriers of Hotel Outsourcing. While outsourcing may be considered highly beneficial for many companies, it can also lead to a number of significant risks if it is not managed properly (Kim, 2006). Dorasamy et al. (2010) have identified the perceived risk factors related to outsourcing, which are; changes in supplier circumstances, supplier failure, and loss of confidential information. In a more detailed view, risks that can be considered when firms involved in outsourcing include; loss of core activities, leveraged by suppliers, loss of strategic flexibility, suffering interruptions of supply, receiving poor quality of supply, fall in employee morale, loss of internal coherence, and loss of intellectual property rights (Hamzah et al., 2010). Built on the literature reviewed, the risks of outsourcing can be summarized under the following headings.

Loss of Control. Managers have often cited loss of control as the reason for not outsourcing some of their functions (Domberger, 1998; Hiamey \& Amenumey, 2013). This includes loss of control over standards, contractors and activities (Raiborn et al., 2009). In a supportive view, Lau and Zhang (2006) claimed that loss of control is the common reason for firms not venturing into outsourcing as it could have implications for 
the brand image of a hotel. In addition, Espino-Rodriguez and Padrón-Robaina (2005) indicated that hospitality managers consider losing control over the services and lack of knowledge about whether supplier has business ethics or not as the most important disadvantages of outsourcing. However, this outsourcing pitfall is affected by the quality of the provider and the service agreement that exists between the provider and the organization (Grauman \& Paul, 2005).

Loss of Internal Capabilities. Domberger (1998) believed that in-house knowledge and skills could also be lost when outsourcing occurs. In the same vein, Hiamey and Amenumey (2013) found that hotels were also concerned about losing internal capabilities because of outsourcing. Moreover, when an outside supplier's performance is not acceptable, it is difficult for the firm to bring the activity back in-house due to the loss of internal skills (Embleton \& Wright, 1998; Lamminmaki, 2003). Therefore, an excessive dependence on a supplier makes it difficult to create internal expertise (EspinoRodriguez \& Padron-Robaina, 2005). Research has also shown that organizations may have to face decreasing organizational productivity, because of this loss of employee skills and knowledge (Berry, 2005). Furthermore, some researchers (Domberger, 1998; Lamminmaki, 2003) noted loss of innovation as another concern of outsourcing.

Cost of Outsourcing. In most cases, saving is the main reason for outsourcing; however, unexpected costs are one of its most common drawbacks (Deloitte, 2005). Cost is another factor inhibiting hotel managers from outsourcing. If hotels do not embark on extensive cost-benefit analysis before outsourcing, there is the likelihood that they will incur more costs (Hiamey \& Amenumey, 2013). Moreover, Song (2008) claimed that hidden cost risk would also occur when firms do outsourcing. It consists of the transaction cost while choosing the outsourcing service provide and the conversion cost while giving hotel's service to providers. What is more serious, if the outsourcing service provider doesn't enable the outsourcing service's quality level to the reasonable level, as entrusting party, the hotel will suffer heavy loss for business stagnation or mistakes. (Hiamey \& Amenumey, 2013).

Promptness and Continuity. Promptness, consistency, and continuity are very important tenets of the hospitality service process. As guests become disenchanted if their services are unduly, delayed and service standards keep on fluctuating. Therefore, some hotels wanted to maintain all the activities that they frequently do under their direct control in order to ensure promptness and continuity in the delivery of the services (Hiamey \& Amenumey, 2013).

Confidential Information. The need for confidentiality in certain areas of an organization's operations is as a factor preventing some of the hotels from outsourcing (Hiamey \& Amenumey, 2013). There are certain aspects of hotel operations that are considered commercial secrets, and therefore, cannot be outsourced. These include survey reports, pay roll systems, employee profiles, labor cost and purchasing specifications as well as marketing and promotion plans (Wan \& Su, 2010). Research conducted by Grauman and Paul (2005) showed that outsourcing human resources activities can increase the risk of losing confidential information including reports, and personal data.

Fall in Employee Morale. Belcourt et al. (2006) considered the effect on employee morale as one of the primary risks of outsourcing. Outsourcing always results in displaced employees (Power et al., 2004; Belcourt et al., 2006). Furthermore, the morale of the remaining employees can be affected too (Kumar \& Eickhoff, 2005). Particularly, if there is not a clear pattern for outsourcing, a feeling of insecure may dominate. Low morale 
may affect productivity of the company and it can lead skilled workers seeking a new job (Kumar \& Eickhoff, 2005).

Organizational Culture. The need to manage different organizational cultures can therefore constitute an impediment to outsourcing. There has also been interest shown in the cultural factor in several hotel-outsourcing studies (Hemmington \& King, 2000; Espino-Rodríguez \& Padrón-Robaina, 2004, 2005a; Espino-Rodríguez \& Gil-Padilla, 2005; Lam \& Han, 2005). Espino-Rodríguez and Gil-Padilla (2005) discussed the importance of ensuring that the employees of suppliers understand a hotel's culture. This issue of differing cultures appears particularly pertinent to restaurant outsourcing in a hotel context. Large hotel companies are often characterized as rigid and slow to adapt, whereas restaurant companies, especially those with celebrity chefs, tend to operate in a flexible and autonomous style. Hemmington and King (2000) claimed that the existing organizational culture is disturbed when an external outsourcing agent enters the hotel (Hemmington \& King, 2000).

Lack of Specialized Suppliers. The unavailability of specialized suppliers is one reason why companies will not consider outsourcing (Corbett, 2004; Ono, 2007). According to Lau and Zhang (2006), when it becomes difficult to locate specialized contractors, companies will continue to perform functions or activities that they would have outsourced. In addition, Hiamey and Amenumey (2013) indicated that some hotels that are already outsourcing find it difficult to outsource certain activities because they cannot find specialized suppliers in the market place.

In a summary, besides its benefits, outsourcing is a practice which may also cause problems like, whether in short or long term, excessive dependence on supplier enterprises, losing confidential information, emergence of communication problems, negative effect on staff, losing control over relevant processes and price pressure of the suppliers (Kakabadse \& Kakabadse, 2000). However, Quinn and Hilmer (1994) highlighted that; both outsourcing decision and carrying on the activities with in house sources have risks. Therefore, if a business can identify its core competencies and procure other services extrinsically and synchronize them cleverly, it will increase capital return, reduce risks, gain flexibility and meet customer needs better with a lower cost.

\section{Research Methodology}

Based on the previous literature review, questions were formulated to reflect the study's primary purpose and objectives:

$\boldsymbol{R Q 1}$. To what extent different hotel functions and activities are currently outsourced by hotels?

$\boldsymbol{R Q}$.2. What are the reasons that drive hotels in Egypt to use outsourcing?

$\boldsymbol{R Q . 3 . ~ W h a t ~ a r e ~ t h e ~ b a r r i e r s ~ t h a t ~ f a c e ~ h o t e l s ~ a n d ~ p r e v e n t ~ t h e m ~ f r o m ~ a p p l y i n g ~}$ outsourcing?

Exploratory research design is deemed appropriate for investigating the outsourcing phenomenon in a detailed way and by identifying variables that can be measured (Creswell, 2002). This was necessary due to the paucity of literature about outsourcing in hotels of Egypt. The applied sampling technique was the stratified random sampling, since it guarantees that every element in the defined population has a known, independent, and equal chance of being selected as a subject, and selection of one element does not affect the selection of another element. 
The target population included General Managers (GMs) or Department Managers (DMs) working in all four and five-star hotels in Egypt at the time of conducting this research. The researchers purposefully selected Cairo and Sharm El-Sheikh for conducting the study. There are both general and specific reasons behind the selection of Cairo and Sharm El-Sheikh cities as the geographical area of the population. The general reason can be encapsulated in the fact that, they are two of the most popular tourist destinations in Egypt, which contains large variety of hotels with different characteristics (e.g. management style, grade) and this is an ideal society for the application of the study. Sharm El-Sheikh was chosen, since Sharm is a consolidated sun and sand tourist segment with signs of maturity, and greater competitiveness owing to the appearance of new tourist destinations and products. This means that the hotels must be more competitive and offer tourists better quality, which may obligate many professionals in the sector to consider new tools of management, such as outsourcing. Cairo was chosen, since Cairo, unlike other cities, does not face extreme seasonality and it has different characteristics concerning service level, operational standards, and target markets. Moreover, as the capital and seat of government of Egypt, Cairo has also seen the proliferation of firms providing services such as security management, catering, information technology, and laundry to most service sectors such as banks and hotels. This trend is important because outsourcing of services in an area depends largely on the availability of such services in that area (Corbett, 2004; Ono, 2007).

A list of four and five star hotels in both Cairo and Sharm El-Sheikh was developed. This list included 155-hotels in total distributed on Cairo; 17 four-star and 33 five-star hotels and Sharm El-Sheikh; 64 four-star and 41 five-star hotels. The sample frame was adopted from the Egyptian Hotel Association website. A stratified-random sample of 48 hotels was taken, representing more than 30 percent of the 155 -hotels population distributed on Cairo; 5 four-star and 10 five-star hotels and Sharm El-Sheikh; 20 four-star and 13 five-star hotels (Table 2).

Table 2: Specifications of the Targeted Population and Selected Sample

\begin{tabular}{|c|c|c|c|c|}
\hline Elements of the Pop & & Four and Five-Star H & els in Cairo \& Sharm E & ikh (155 Hotels) \\
\hline Sampling Design & & Probability Sampling & & \\
\hline Sampling Technique & & Stratified Random Sa & pling & \\
\hline Sample Size & & 48 Hotels (23 Five-St & , and 25 Four-Star Hot & \\
\hline Sample Subjects & & General Managers/De & artment Managers & \\
\hline Time Period & & $31 / 01 / 2015-22 / 3 / 20$ & & \\
\hline City & Category & Number of Hotels & $\%$ of the Population & $\begin{array}{c}\text { Sample Size } \\
\mathbf{3 0} \%\end{array}$ \\
\hline Cairo & 4 & 17 & $11 \%$ & 5 \\
\hline (City hotels) & 5 & 33 & $22 \%$ & 10 \\
\hline Sharm El-Sheikh & 4 & 64 & $41 \%$ & 20 \\
\hline (Resorts) & 5 & 41 & $26 \%$ & 13 \\
\hline To & & 155 & $100 \%$ & 48 \\
\hline
\end{tabular}

Source: Egyptian Hotel Association (2013)

Data was collected through a structured questionnaire. The questionnaire was composed of four sections. The first section was concerned with determining the types of functions outsourced by hotels. In line with this objective, a list of hotel activities, which 
are commonly outsourced by hotels, is developed based on the work of Lamminmaki (2003), Espino-Rodriguez and Padron-Robaina (2004; 2005), Bolat and Y1lmaz (2009), and Hiamey and Amenumey (2013). The developed list of hotel activities included 32hotel activity. In order for the managers to indicate the current level of outsourcing application, they were asked to determine the extent to which those activities are outsourced using a 3-point Likert scale, where (1) means that no part of the operation is outsourced, (2) means partially outsourced, and (3) means totally outsourced to an outside service provider.

The second section of the questionnaire was concerned with the reasons for outsourcing in hotels. In this section, managers were asked to indicate on a 5-point Lickert scale (where "1" means strongly disagree and "5" means strongly agree), the extent to which 11 items represent the reasons that have been driven hotels to adopt outsourcing. Those items were divided into three dimensions; (1) focusing on core activities, (2) lack of internal capabilities and (3) cost reduction. Each dimension has its own unique points in investigating the reasons of outsourcing. This scale was built on the work of Ghodeswar and Vaidyanathan (2008) and Baytok et al. (2013).

The third section of the questionnaire was concerned with the barriers and the challenges facing outsourcing from hotel managers' point of view. In this section, managers were asked to indicate on a 5-point Lickert scale, (where "1" means strongly disagree and "5" means strongly agree), the extent to which 13 items represent the factors that faced or may face them and prevent hotels from adopting outsourcing. Those items are developed based on the work of Lam and Ham (2005), Maelah et al. (2010) and Baytok et al. (2013). This section is also followed by an open-ended question that invites hotel managers to reveal whether there are any other barriers, or risks related to outsourcing, thus preventing them from adopting it.

The last section was concerned with collecting personal data including; managers' gender, age, nationality, e-mail, years of experience and educational background as well as hotel profile characteristics such as; management structure, hotel type, size and number of employees.

The data were analyzed using the Statistical Package for the Social Sciences (SPSS 18.0). Descriptive statistics i.e. mean, standard deviation, frequency, and percent, of each data set are provided to illustrate the findings.

\section{Results and Findings}

Managers' and Hotels' Profile Characteristics. Using descriptive statistics, i.e. frequency, and percent, the characteristics of the respondents as well as the hotel properties are analyzed and reported. Tabulated features of managers' profile included educational background, managers' experience in the hospitality industry as well as whether managers have received hospitality education, while hotels' profile included management structure, type, size and category. For the sake of simplicity and ease of displaying data in this preliminary phase, the characteristics of the respondents and the hotel properties are provided in a tabulated form (Table 3 ).

Initial analysis of the demographic data indicated that almost all respondents were male managers $(95.8 \%)$; managers were, on average, 37 years old. In view of their educational background, the majority of managers $(81 \%)$ had a university degree, while $14.6 \%$ of them had a high school, and only $4.2 \%$ had a master degree. The number of managers 
who received formal hospitality education (50\%) is equal to those who did not $(50 \%)$. As for managers' experience in the hospitality industry, the largest number of managers had an experience between 11-20 years (77.1\%). In terms of job position, General Managers make up $16.7 \%$ of the respondents, while Department Managers constituted 83.3 \%. Department Managers included front office managers $(27.1 \%)$, human resources managers $(16.7 \%)$, food and beverage managers $(10.4 \%)$, sales and marketing managers $(6.3 \%)$, housekeeping managers $(6.3 \%)$, director of rooms $(4.2 \%)$ and other Department Heads (12.6\%) including (IT manager, training manager, duty manager, operation manager, quality manager, and financial controller). This result was good since all respondents were senior managers as required for this study because they are likely to be highly knowledgeable about their hotel outsourcing decisions.

As for hotels' profile, the number of sampled four and five-star hotels were almost equal. The majority of hotels were chain-affiliated $(62.5 \%)$, while $(37.5 \%)$ were independent hotels. The hotels were classified into three different categories based on hotel size as indicated by the number of guest rooms (less than 100 rooms for small, $100-$ 299 rooms for medium and more than 300 rooms for large). Promsivapallop (2009) used this classification in their study of hotel outsourcing using critical incident technique to identify factors influencing the decision. In this study, more than half $(52.1 \%)$ of the sampled hotels were large with 300 rooms and over, followed by medium sized hotels that had from 100_299 rooms (43.8\%). In respect to the number of employees, $(50 \%)$ of responding hotels had from 100-299 employees, followed by large hotels that had 300 and over employees $(37.5 \%)$, and the least number of managers worked for hotels with less than 100 employees (12.5\%). In terms of type, approximately $68.8 \%$ of the sampled hotels were resorts, while city hotels comprised about $31.3 \%$ of the sample. A hotel has been viewed as a 'city hotel' if it is located in Cairo and a 'resort hotel' if it is located in Sharm El-Sheikh. Like hotel category, this variable was not measured in the questionnaire, since this information was derived from the EHA Guide 2013.

Table 3: Respondents' Profiles and Hotel Characteristics

\begin{tabular}{|c|c|c|c|c|c|}
\hline \multicolumn{3}{|c|}{ Managers' Profile Characteristics } & \multicolumn{3}{|c|}{ Hotels'Profile Characteristics } \\
\hline Gender & Fre & $\%$ & Class & Fre & $\%$ * \\
\hline Male & 46 & 95.8 & 4 stars & ro & Or, \\
\hline Female & 2 & 4.2 & 5 stars & rT & $\varepsilon \vee, q$ \\
\hline \multicolumn{3}{|c|}{ Educational background } & \multicolumn{3}{|c|}{ Number of Employees } \\
\hline High School & 7 & 14.6 & Less than 100 & 7 & $1,1,0$ \\
\hline University Degree & 39 & 81.3 & $100-299$ & $r \varepsilon$ & 0. \\
\hline Master Degree & 2 & 4.2 & 300 and over & 11 & $r V, 0$ \\
\hline \multicolumn{3}{|c|}{ Years of Experience } & \multicolumn{3}{|c|}{ Number of Rooms } \\
\hline 10 or less Years & 4 & 8.3 & Less than 100 & $r$ & $\overline{\varepsilon, r}$ \\
\hline $11-20$ Years & 37 & 77.1 & $100-299$ & Y) & $\varepsilon \Gamma, \wedge$ \\
\hline $21-30$ Years & 7 & 14.6 & 300 and over & ro & or, 1 \\
\hline \multicolumn{3}{|l|}{ Age } & \multicolumn{3}{|c|}{ Location/ Type } \\
\hline 30 or less & 1 & 2.1 & \multirow[t]{2}{*}{ Sharm El-Sheikh (Resorts) } & \multirow{2}{*}{ r } & \multirow{2}{*}{$\uparrow \wedge, \wedge$} \\
\hline $31-40$ & 30 & 62.5 & & & \\
\hline $41-50$ & 17 & 35.4 & \multirow[t]{2}{*}{ Cairo (City hotels) } & \multirow{2}{*}{10} & \multirow{2}{*}{ r, } \\
\hline Average & \multicolumn{2}{|c|}{37 years } & & & \\
\hline
\end{tabular}




\begin{tabular}{|c|c|c|c|c|c|}
\hline \multicolumn{3}{|l|}{ Nationality } & \multicolumn{3}{|l|}{ Management Structure } \\
\hline Egyptian & 47 & 97.9 & Independent & 11 & $r v, 0$ \\
\hline Other & 1 & 2.1 & Belongs to a chain & $r \cdot$ & $T r, 0$ \\
\hline \multicolumn{6}{|l|}{ Professional Title (position( } \\
\hline General Manager & 8 & 16.7 & Other Department Heads & 7 & $1 Y, 7$ \\
\hline Front office Manager & 13 & 27.1 & Financial Controller & 1 & $r, 1$ \\
\hline Human Resource Manager & 8 & 16.7 & IT Manager & 1 & $r, 1$ \\
\hline Food \& Beverage Manager & 5 & 10.4 & Quality Manager & 1 & 2.1 \\
\hline Housekeeping Manager & 3 & 6.3 & Training Manager & 1 & $r, 1$ \\
\hline Sales \& Marketing Manager & $r$ & $7, r$ & Duty Manager & 1 & $r, 1$ \\
\hline Director of Rooms & r & $\varepsilon, Y$ & Operation Manager & 1 & 2.1 \\
\hline \multirow{2}{*}{\multicolumn{4}{|c|}{ Did you have an academic (formal) hospitality education before? }} & Yes & No \\
\hline & & & & $50 \%$ & $\% 0$ \\
\hline
\end{tabular}

Types and Levels of Functions Outsourced. Table 4 shows the current outsourcing level for each activity. The overall outsourcing level is ( $\overline{\mathbf{x}}$ : 1.75). Activities can be classified by mean value into three categories; highly outsourced, medium outsourced and low outsourced activities. The first category includes high-outsourced activities with mean value between 2.34 and 3 . This category reveals the most outsourced hotel activities respectively as; software installation $(\overline{\mathbf{x}} \mathbf{2} \mathbf{2 . 8 5})$, pest controllHK $(\overline{\mathbf{x}}: \mathbf{2 . 7 9})$, quality inspection ( $\overline{\mathbf{x}}: \mathbf{2 . 6 8})$, limousine services $(\overline{\mathbf{x}}: \mathbf{2 . 5 6})$, and health club $(\overline{\mathbf{x}}: \mathbf{2 . 5 2})$. In addition, staff transportation $(\overline{\mathbf{x}}: \mathbf{2 . 7 8})$, and animation services $(\overline{\mathbf{x}} \mathbf{2} \mathbf{2 . 4 5})$, were among the most outsourced activities by hotels, however these activities were found only in resorts (Sharm El-Sheikh), but does not exist in city hotels (Cairo), where city hotels do not provide staff transportation nor animation services.

The second category comprises medium outsourced activities with mean value between 1.67 and 2.33. This category includes the following activities; software maintenance and update $(\overline{\mathbf{x}}: \mathbf{2 . 1 4})$, routine cleaning $(\overline{\mathbf{x}}: \mathbf{2 . 1 2})$, marketing $(\overline{\mathbf{x}}: \mathbf{2 . 0 0})$, reservations $(\overline{\mathbf{x}}: \mathbf{1 . 9 5})$, payroll ( $\overline{\mathbf{x}}: \mathbf{1 . 8 3})$, floral services and design $(\overline{\mathbf{x}}: \mathbf{1 . 8 1})$, lift maintenance $(\overline{\mathbf{x}}: \mathbf{1 . 8 1})$, and audiovisual equipment $(\overline{\mathbf{x}}: \mathbf{1 . 7 7})$. The third category of low or never outsourced activities with mean between 1 and 1.66, this category includes the following activities; training $(\overline{\mathbf{x}}$ : 1.66), security $(\overline{\mathbf{x}}: \mathbf{1 . 6 2})$, customer satisfaction research $(\overline{\mathbf{x}}: \mathbf{1 . 5 0})$, recruiting $(\overline{\mathbf{x}}: \mathbf{1 . 4 1})$, waste management $(\overline{\mathbf{x}}: \mathbf{1 . 3 3})$, gardening/landscaping $(\overline{\mathbf{x}}: \mathbf{1 . 3 1})$, swimming pool maintenance ( $\overline{\mathbf{x}}: \mathbf{1 . 2 9})$, laundry ( $\overline{\mathbf{x}}: \mathbf{1 . 1 8})$, parking services $(\overline{\mathbf{x}}: \mathbf{1 . 1 6})$, purchasing $(\overline{\mathbf{x}}: \mathbf{1 . 1 4})$, public relations ( $\overline{\mathbf{x}}: \mathbf{1 . 1 4})$, pre-prepared ingredients $(\overline{\mathbf{x}}: \mathbf{1 . 1 0})$, air conditioning maintenance $(\overline{\mathbf{x}}: \mathbf{1 . 0 8})$, restaurants $\backslash$ discos $(\overline{\mathbf{x}}: \mathbf{1 . 0 4})$, room cleaning $(\overline{\mathbf{x}}: \mathbf{1 . 0 2})$, accounting $(\overline{\mathbf{x}}: \mathbf{1 . 0 2})$, and bellmanlconcierge $(\overline{\mathbf{x}}: \mathbf{1 . 0 0})$. 
Table 4: Levels of Outsourcing Application in Hotels

\begin{tabular}{|c|c|c|c|c|c|c|c|c|}
\hline \multirow{3}{*}{$\begin{array}{c}\text { Hotel } \\
\text { Departments/Activities }\end{array}$} & \multicolumn{8}{|c|}{ Current Level of Outsourcing } \\
\hline & \multicolumn{2}{|c|}{$\begin{array}{c}\text { Not } \\
\text { Outsourced } \\
1 \\
\end{array}$} & \multicolumn{2}{|c|}{$\begin{array}{c}\text { Partially } \\
\text { Outsourced } \\
2 \\
\end{array}$} & \multicolumn{2}{|c|}{$\begin{array}{c}\text { Totally } \\
\text { Outsourced } \\
3 \\
\end{array}$} & \multirow{2}{*}{$\begin{array}{l}\text { Mean } \\
\qquad \overline{\mathbf{x}}\end{array}$} & \multirow[t]{2}{*}{ SD } \\
\hline & Fre $^{*}$ & $\%$ & Fre & $\%$ & Fre & $\%$ & & \\
\hline Human Resources & & & & & & & 1.54 & .383 \\
\hline Recruiting & 28 & 58.3 & 20 & 41.7 & 0 & 0 & 1.41 & .498 \\
\hline Training & 18 & 37.5 & 28 & 58.3 & 2 & 4.2 & 1.66 & .558 \\
\hline Front office & & & & & & & 1.51 & .192 \\
\hline Reservations & 5 & 10.4 & 40 & 83.3 & 3 & 6.3 & 1.95 & .410 \\
\hline Bellman/concierge & 48 & 100 & 0 & 0 & 0 & 0 & 1.00 & .244 \\
\hline Housekeeping & & & & & & & 1.78 & .307 \\
\hline Room cleaning & 47 & 97.9 & 1 & 2.1 & 0 & 0 & 1.02 & .144 \\
\hline Routine cleaning e.g., marble, glass, & 12 & 25 & 18 & 37.5 & 18 & 37.5 & 2.12 & .788 \\
\hline Pest Control/fumigation & 5 & 10.4 & 0 & 0 & 43 & 89.6 & 2.79 & .617 \\
\hline Laundry & 44 & 91.6 & 3 & 6.3 & 1 & 2.1 & 1.18 & .532 \\
\hline Food \& Beverage & & & & & & & 1.59 & .256 \\
\hline Restaurants, Discos & 47 & 97.9 & 0 & 0 & 1 & 2.1 & 1.04 & .288 \\
\hline $\begin{array}{l}\text { Prepared ingredients (e.g., pastry, } \\
\text { baking) }\end{array}$ & 44 & 91.6 & 3 & 6.3 & 1 & 2.1 & 1.10 & .371 \\
\hline Quality inspection & 1 & 2.1 & 13 & 27.1 & 34 & 70.8 & 2.68 & .511 \\
\hline Convention \& Banquet & & & & & & & 1.79 & .713 \\
\hline Audiovisual/equipment & 20 & 41.7 & 19 & 39.6 & 9 & 18.8 & 1.77 & .750 \\
\hline Floral services and design & 23 & 47.9 & 11 & 22.9 & 14 & 29.2 & 1.81 & .866 \\
\hline Information Technology (IT) & & & & & & & 2.50 & .399 \\
\hline Software-Installation & 1 & 2.1 & 5 & 10.4 & 42 & 87.5 & 2.85 & .412 \\
\hline Maintenance and update & 4 & 8.3 & 33 & 68.8 & 11 & 22.9 & 2.14 & .545 \\
\hline Engineering \& Maintenance & & & & & & & 1.37 & .481 \\
\hline Lift maintenance ${ }^{* *}$ & 20 & 41.6 & 15 & 31.3 & 12 & 25.0 & 1.81 & .816 \\
\hline Pool maintenance ${ }^{* *}$ & 38 & 79.2 & 7 & 14.6 & 2 & 4.2 & 1.29 & .650 \\
\hline Air conditioning maintenance & 45 & 93.8 & 2 & 4.2 & 1 & 2.1 & 1.08 & .347 \\
\hline Gardening/landscaping ${ }^{* *}$ & 42 & 87.5 & 0 & 0 & 3 & 6.3 & 1.31 & .854 \\
\hline Transportation Services & & & & & & & 2.86 & .562 \\
\hline Staff transportation ${ }^{* * *}$ & 1 & 3 & 5 & 15.2 & 27 & 81.8 & 2.78 & .484 \\
\hline Limousine & 9 & 18.8 & 3 & 6.3 & 36 & 75 & 2.56 & .796 \\
\hline Marketing \& Sales & 1 & 2.1 & 46 & 95.8 & 1 & 2.1 & 2 & .206 \\
\hline Public Relations & 44 & 91.7 & 1 & 2.1 & 3 & 6.3 & 1.14 & .504 \\
\hline Purchasing & 42 & 87.5 & 5 & 10.4 & 1 & 2.1 & 1.14 & .412 \\
\hline Security & 30 & 62.5 & 6 & 12.9 & 12 & 25 & 1.62 & .866 \\
\hline Accounting & 47 & 97.9 & 1 & 2.1 & 0 & 0 & 1.02 & .144 \\
\hline Payroll (salary payment) & 14 & 29.2 & 28 & 58.3 & 6 & 12.5 & 1.83 & .630 \\
\hline Health club & 10 & 20.8 & 4 & 8.3 & 33 & 68.8 & 2.52 & .850 \\
\hline Parking Services & 44 & 91.7 & 0 & 0 & 4 & 8.3 & 1.16 & .558 \\
\hline Waste Management & 37 & 77.1 & 6 & 12.5 & 5 & 10.4 & 1.33 & .663 \\
\hline Animation/Leisure Activities $^{* * *}$ & 8 & 24.2 & 2 & 6.1 & 23 & 69.7 & 2.45 & .869 \\
\hline Customer Satisfaction Survey & 28 & 58.3 & 16 & 33.3 & 4 & 8.4 & 1.50 & .652 \\
\hline Total Mean & & & & & & & 1.75 & .200 \\
\hline
\end{tabular}


$\overline{\mathrm{x}}=$ Mean $\quad \mathrm{SD}=$ Standard Deviation $\quad$ Fre*_- Frequency $* *$ - Some hotels indicated that this activity does not exist, ***_ Activities were found only in Sharm El-Sheikh.

Reasons for Outsourcing. According to the results (table 5), the most important reason for outsourcing in hotels, compared to others, was "To obtain technologies which otherwise will not

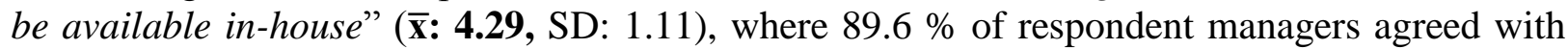
this statement. The second highly ranked reason for using outsourcing was "To obtain expertise,

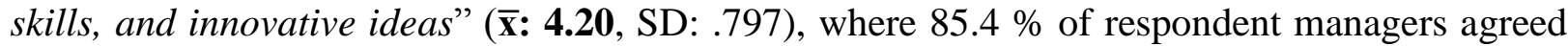
with this statement. The third highly ranked reason was "To gain access to products, services

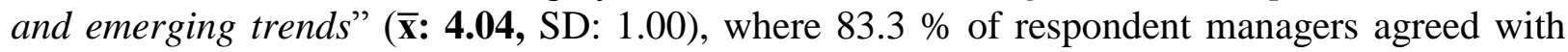
this statement. As shown in Table 5, these three highly ranked statements represent and measure the "expertise search" construct. This indicates the importance of expertise search as an essential driver for outsourcing in hotels $(\overline{\mathbf{x}}: \mathbf{4 . 1 8}$, SD: .807).

Table 5: Reasons for Outsourcing in Hotels

\begin{tabular}{|c|c|c|c|c|c|c|c|}
\hline \multirow[t]{2}{*}{ Reasons for Outsourcing in Hotels } & \multirow{2}{*}{$\underset{\bar{\chi}}{\operatorname{Mean}}$} & \multirow[t]{2}{*}{ SD } & 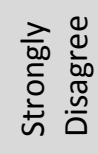 & 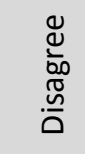 & $\begin{array}{l}\bar{\pi} \\
\stackrel{5}{5} \\
\frac{\pi}{2}\end{array}$ & $\frac{0}{\frac{0}{00}}$ & 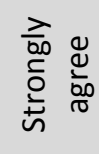 \\
\hline & & & $\%$ & $\%$ & $\%$ & $\%$ & $\%$ \\
\hline Focusing on core activities & 3.70 & .729 & & & & & \\
\hline 1. To achieve a greater focus on core activities & 3.72 & 1.02 & -- & 16.7 & 18.8 & 39.6 & 25 \\
\hline $\begin{array}{l}\text { 2. To increase flexibility to deal with seasonality and } \\
\text { fluctuation in demand }\end{array}$ & 3.79 & .944 & 2.1 & 6.3 & 25 & 34.8 & 22.9 \\
\hline $\begin{array}{l}\text { 3. To redirect resources from non-core activities to } \\
\text { greater focus in serving the customer }\end{array}$ & 3.31 & .926 & -- & 22.9 & 31.3 & 37.5 & 8.3 \\
\hline $\begin{array}{l}\text { 4. To improve operating performance, quality, } \\
\text { timeliness, and productivity }\end{array}$ & 4.00 & 1.00 & 2.1 & 6.3 & 16.7 & 37.5 & 35.4 \\
\hline Expertise search & 4.18 & .807 & & & & & \\
\hline 1. To obtain expertise, skills, and innovative ideas & 4.20 & .797 & -- & 4.2 & 10.4 & 45.8 & 39.6 \\
\hline $\begin{array}{l}\text { 2. To obtain technologies which otherwise will not be } \\
\text { available in-house }\end{array}$ & 4.29 & 1.11 & 6.3 & 4.2 & -- & 33.3 & 56.3 \\
\hline $\begin{array}{l}\text { 3. To gain access to products, services and emerging } \\
\text { trends }\end{array}$ & 4.04 & 1.00 & 2.1 & 10.4 & 4.2 & 47.9 & 35.4 \\
\hline Reducing Costs & 3.72 & .767 & & & & & \\
\hline $\begin{array}{l}\text { 1. To reduce operating costs (energy, raw materials, } \\
\text { etc.,) }\end{array}$ & 3.75 & .978 & 2.1 & 8.3 & 25 & 41.7 & 22.9 \\
\hline 2. To reduce staff costs e.g., salary, uniform, etc. & 3.62 & 1.16 & 4.2 & 16.7 & 16.7 & 37.5 & 25 \\
\hline 3. To transform fixed costs to variable costs & 3.89 & .831 & -- & 4.2 & 27.1 & 43.8 & 25 \\
\hline $\begin{array}{l}\text { 4. To reduce the need for capital especially in non-core } \\
\text { business functions }\end{array}$ & 3.62 & 1.12 & 4.2 & 14.6 & 18.8 & 39.6 & 22.9 \\
\hline Total Mean & 3.87 & .502 & & & & & \\
\hline
\end{tabular}

SD: Standard Deviation 
As shown in Table 5, other highly ranked reasons for outsourcing were; "To improve operating performance, quality, timeliness, and productivity" ( $\overline{\mathbf{x}}: \mathbf{4 . 0 0}$, SD: 1.00$)$, where $72.9 \%$ of respondent managers agreed with this statement. Followed by "To transform fixed costs to variable costs" ( $\overline{\mathbf{x}}$ : 3.89, SD: .831), where $63.8 \%$ of respondents agreed with this statement, and "To increase flexibility

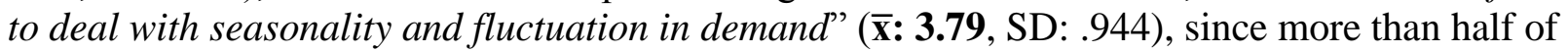
respondents $(57.7 \%)$ agreed with this statement.

Barriers of Outsourcing. According to the results, the overall average mean score obtained from the 13 barriers statements is $(\overline{\mathbf{x}}: 3.09$, SD: .538), which indicates that outsourcing suffers from certain barriers and challenges. As shown in Table 7, the most significant barrier faces hotel managers and obstacles the use of outsourcing is "Lack of reliable outsourcing suppliers in the

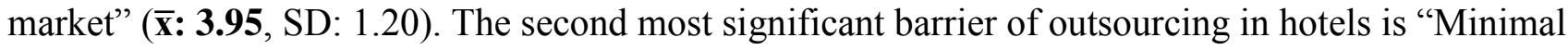
knowledge concerning outsourcing adoption process and benefits" ( $\overline{\mathbf{x}}: \mathbf{3 . 3 1}$, SD: 1.14), and the third most significant barrier of outsourcing is "a possible risk of providing unqualified staff" ( $\overline{\mathbf{x}}: \mathbf{3 . 2 9}$, SD: .921). The least ranked barriers of outsourcing compared to others are; losing control over the outsourced functions ( $\overline{\mathbf{x}}: \mathbf{2 . 6 8}$, SD: .948), and the cultural differences between the hotel and the outsourcing supplier ( $\overline{\mathbf{x}}: \mathbf{2 . 6 8}, \mathrm{SD}: .948)$. It can also be seen that the standard deviation value for many statements is more than one $(S D>1)$, indicating that managers were different in their views of outsourcing barriers.

Table 6: Barriers of Outsourcing in Hotels

\begin{tabular}{|c|c|c|c|c|c|c|c|}
\hline \multirow[t]{2}{*}{ Barriers of Outsourcing } & \multirow[t]{2}{*}{$\stackrel{\text { Mean }}{\bar{\chi}}$} & \multirow[t]{2}{*}{ SD } & 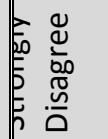 & 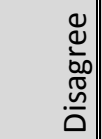 & $\begin{array}{l}\overline{0} \\
\stackrel{0}{ \pm} \\
\frac{0}{2} \\
Z\end{array}$ & $\underset{\frac{1}{d}}{\frac{0}{00}}$ & 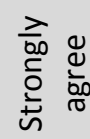 \\
\hline & & & $\%$ & $\%$ & $\%$ & $\%$ & $\%$ \\
\hline 1. Lack of reliable outsourcing suppliers in the market & 3.95 & 1.20 & -- & 22.9 & 4.2 & 27.1 & 45.8 \\
\hline $\begin{array}{l}\text { 2. Lack of experience and expertise in managing } \\
\text { outsourcing contracts }\end{array}$ & 3.16 & 1.01 & 4.2 & 29.2 & 14.6 & 50 & 2.1 \\
\hline $\begin{array}{l}\text { 3. Lack of experience in monitoring outsourcing } \\
\text { suppliers }\end{array}$ & 2.89 & .994 & 6.3 & 33.3 & 27.1 & 31.3 & 2.1 \\
\hline $\begin{array}{l}\text { 4. Minimal knowledge concerning outsourcing adoption } \\
\text { process and benefits }\end{array}$ & 3.31 & 1.14 & 8.4 & 22.8 & 20.7 & 33.5 & 14.6 \\
\hline $\begin{array}{l}\text { 5. Losing of internal expertise in the outsourced } \\
\text { functions }\end{array}$ & 2.93 & 1.15 & 6.3 & 37.5 & 25 & 18.8 & 12.5 \\
\hline 6. Losing control over the outsourced functions & 2.68 & .948 & 2.1 & 54.2 & 20.8 & 18.8 & 4.2 \\
\hline 7. A possible risk of poor service delivery & 3.14 & .898 & -- & 27.1 & 37.5 & 29.2 & 6.3 \\
\hline 8. A possible risk of providing unqualified staff & 3.29 & .921 & -- & 22.9 & 33.3 & 35.4 & 8.3 \\
\hline 9. A possible risk of terminating employees & 2.83 & 1.24 & 12.5 & 35.4 & 20.8 & 18.8 & 12.5 \\
\hline 10. A fall in employee morale & 2.85 & 1.03 & 10.4 & 20.8 & 50.0 & 10.4 & 8.3 \\
\hline 11. Being worried about hotel's confidential information & 3.08 & 1.28 & 12.5 & 25 & 18.8 & 29.2 & 14.6 \\
\hline $\begin{array}{l}\text { 12. The cultural differences between the hotel and } \\
\text { outsourcing supplier }\end{array}$ & 2.68 & .948 & 4.2 & 52.1 & 14.6 & 29.2 & -- \\
\hline $\begin{array}{l}\text { 13. Hidden costs related to outsourcing such as searching } \\
\text { and negotiating costs }\end{array}$ & 3.22 & .972 & 2.1 & 22.9 & 33.3 & 33.3 & 8.3 \\
\hline Total Mean & 3.09 & .538 & & & & & \\
\hline
\end{tabular}

SD: Standard Deviation 


\section{Discussion}

Hotels in Egypt partially outsource their services and activities. This means that hotels give out part of their departments rather than an entire department. This activity specific understanding of outsourcing given by the managers coincides with a definition provided by Broedner et al., (2009) who denoted outsourcing, as "a vertical scope decision by which only parts of the process are supplied from outside while the process capability to cover the rest remains in-house". In supportive view, it was found that a hotel may outsource security but not the security manager, or a hotel may outsource laundry but not the ownership of linen. This is in line with the admonishment by Stroh and Treehuboff (2003) that companies should consider outsourcing individual activities rather than the duties of an entire department due to the need to maintain some in-house expertise in every area.

The findings of the research indicate that the overall outsourcing level in the Egyptian hotel market is relatively medium. Furthermore, eight of the 32 activities appraised recorded medium outsourcing levels representing the medium activities outsourced in hotels. These activities are software maintenance and update, routine cleaning, marketing, reservations, payroll, floral services and design, lift maintenance, and audiovisual equipment.

The top most activities outsourced within hotels indicated that hotel core activities were not outsourced. Almost all activities outsourced can be seen as supportive or peripheral to hotel operations. This goes in hand with the core competency approach, where outsourcing of non-core hotel activities can lead to the improvement of hotels' focus upon the core competencies and thus increase hotels' performance because hotels can direct its attention and resources toward service quality and customer satisfaction.

Table 7: Activities Grouped According to their Outsourcing Level

\begin{tabular}{|l|l|}
\hline Group & Activity \\
\hline Group A: Highly-Outsourced Activities & Software Production and Installation \\
& Pest Control \\
& Quality Inspection \\
Limousine Services \\
Group B: Medium-Outsourced Activities & Health Club \\
& Staff Transportation \\
& Animation Services \\
& Software Maintenance and Update \\
& Routine Cleaning \\
& Marketing \\
& Reservations \\
\hline Group C: Low-Outsourced Activities & Payroll \\
& Floral Services and Design \\
& Lift Maintenance \\
& Audiovisual Equipment \\
\hline & Training \\
& Security \\
& Customer Satisfaction Research \\
& Recruiting \\
& Waste Management \\
& Gardening/Landscaping \\
& Swimming Pool Maintenance \\
\hline
\end{tabular}




\begin{tabular}{|l|l|}
\hline Group & Activity \\
\hline & Parking Services \\
& Purchasing \\
& Public Relations \\
& Pre-Prepared Ingredients \\
& Air Conditioning \\
& Restaurants\Discos \\
& Room Cleaning \\
& Accounting \\
& Bellman\Concierge \\
\hline
\end{tabular}

Hotels incline towards outsourcing in line with certain purposes and aims. In Egypt, hotels showed mixed reasons for venturing into outsourcing. As shown in figure 1, the reasons included, respectively, expertise search, cost reduction and focusing on core activities.

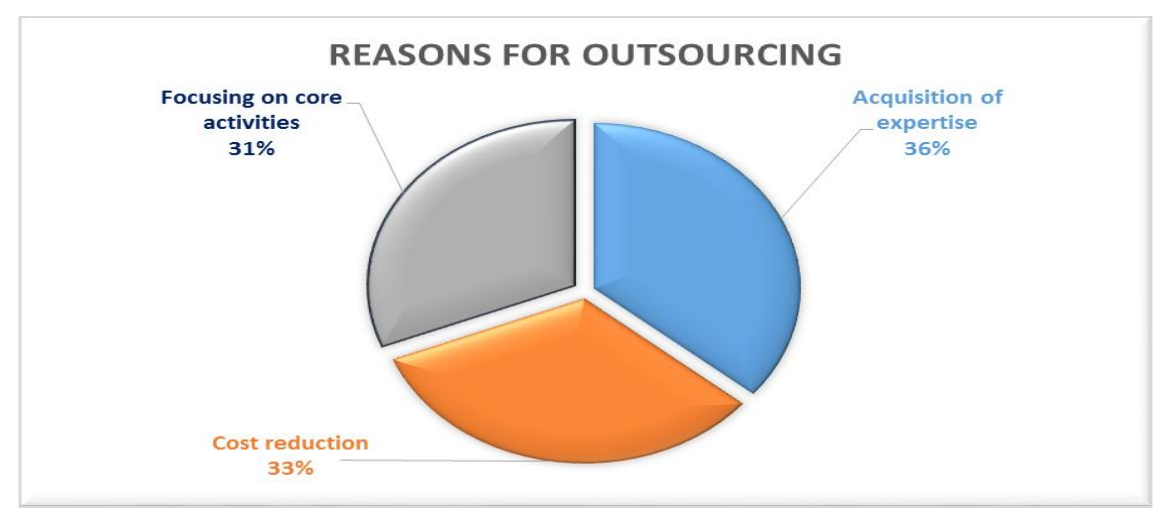

Figure 1: Reasons for Outsourcing in the Egyptian Hotel Market

Cost reduction used to be the primary reason for considering outsourcing in many studies (Corbett, 2004; Espino-Rodriguez \& Padron-Robaina, 2005; Donada \& Nogatchewsky, 2009; McIvor, 2009; Baytok et al., 2013; Bolat et al., 2009). In this study, however, the acquisition of external expertise is the number one driver for using outsourcing by hotels in Egypt. This indicates that outsourcing has not always been undertaken in order to cut down cost but to get outside expertise in areas where an organization lacks the capacity. This is consistent with the study of Sani et al. (2013) and supported by Hiamey and Amenumey (2013), who explored service outsourcing in 3-5 Star hotels in Ghana; they found accessing external expertise was the most cited reason by hotels for venturing into outsourcing. This is in line with the critical shift in focus over recent years, as outsourcing efforts become more mature and clients are no longer looking only for cost economies, but also for a business partner who can contribute to the strategic efforts of the company by providing it with expertise and competencies that are not found in-house (Kremic et al., 2006; Holcomb \& Hitt, 2007; Raiborn, Butler \& Massoud, 2009).

Furthermore, Cost reduction was the second most significant dimension for venturing into outsourcing by hotels in Egypt. This is in line with the reviewed literature where, cost reduction was one of the main reasons why companies adopt outsourcing (Corbett, 2004; Donada \& Nogatchewsky, 2009; Espino-Rodriguez \& Padron-Robaina, 2005; McIvor, 2009). Because greater efficiency is a goal of any management team, with the main objective of achieving maximum output from minimum input (Leavitt et al., 1989). 
Naturally, Hotels always compare the cost of carrying out a function in-house and the cost of getting the service or activity from outside contractors to justify outsourcing (Kremic et al., 2006). This is consistent to the view of Simon (2010) who sated that organizations outsource because they can get the best talent in a highly specialized area and not have to carry them on their payroll.

Another reason for venturing into outsourcing by the hotels is focusing on core activities. The majority of participants agreed that focusing on core activities was a significant factor affecting the outsourcing adoption decision. This goes in hand with the findings of Sriwongwanna (2009), where the majority of participants identified the focus on core competency as a significant factor affecting organizational decision making, and possibly affecting organizational performance when it comes to outsourcing. This is in line with many previous researches and studies that had cited focusing on core areas as a major motive for outsourcing (Espino-Rodriguez \& Padron-Robaina, 2005; McIvor, 2009; Sriwongwanna, 2009).

An overall evaluation of the results pointed out that hotels do not face the common barriers of outsourcing, since many of the barriers examined received a low mean value while managers emphasized some items as the constraints of outsourcing in Egypt (Figure 2). The standard deviation figures were high in most statements indicating that the level of outsourcing was widely diverse among the responding hotels. Therefore, all these barriers are discussed below based on the managers' comments and perceptions.

Lack of reliable outsourcing suppliers in the market was cited as the most significant barrier for outsourcing in hotels, which goes in line with many previous researches and studies (e.g. Corbett, 2004; Ono, 2007; Lamminmaki, 2007; Lai, 2007; Lam \& Han, 2005). Ono (2007), for instance, assured that the unavailability of specialized suppliers is one reason why companies will not consider outsourcing. For this reason, some hotels reported that they were considering back sourcing the health club due to the limited number of competent service providers in the area. This is similar to the study of Lau and Zhang (2006), who concluded that when it becomes difficult to locate specialized contractors, companies would continue to perform functions or activities in house. Some respondents also referred to the difficulty of negotiation when there are few service providers in a specific area. On the other hand, increasing the number of suppliers will result in lower outsourcing prices and higher use of outsourcing by hotels. These findings confirm the previous literature by Lamminmaki (2007), Lai (2007), Lam and Han (2005) in the hotel industry.

The second most cited barrier for outsourcing application was minimal knowledge concerning outsourcing adoption process and benefits. In this respect, Power et al. (2006) commented, "Most organizations fail to admit and recognize that their knowledge of the outsourcing life cycle and management discipline is minimal". With no doubt, outsourcing is a complex business strategy and to be successful, organizations must identify, establish, and implement proven methodologies and industry best practices. Therefore, managers should understand the steps of the outsourcing life cycle, including strategy formulation, requests for proposal, vendor identification and selection, contract negotiation, project transition and outsourcing relationship management.

Most of the managers involved in the study also cited a possible risk of providing unqualified staff by the outsourcing companies as a major concern especially in areas like security, pest control, and recruiting agencies. Many hotel managers highlighted the issue of unqualified workers that were brought in to the hotel through the service provider, as 
they did not meet the criteria set by the hotels and therefore, needed to be given extra training upon arrival. The concerns expressed by the managers in this study are similar to the findings of Knox (2010) concerning the use of temporary workers in hotels in Australia, where managers complained of low quality standards of outsourced staff.

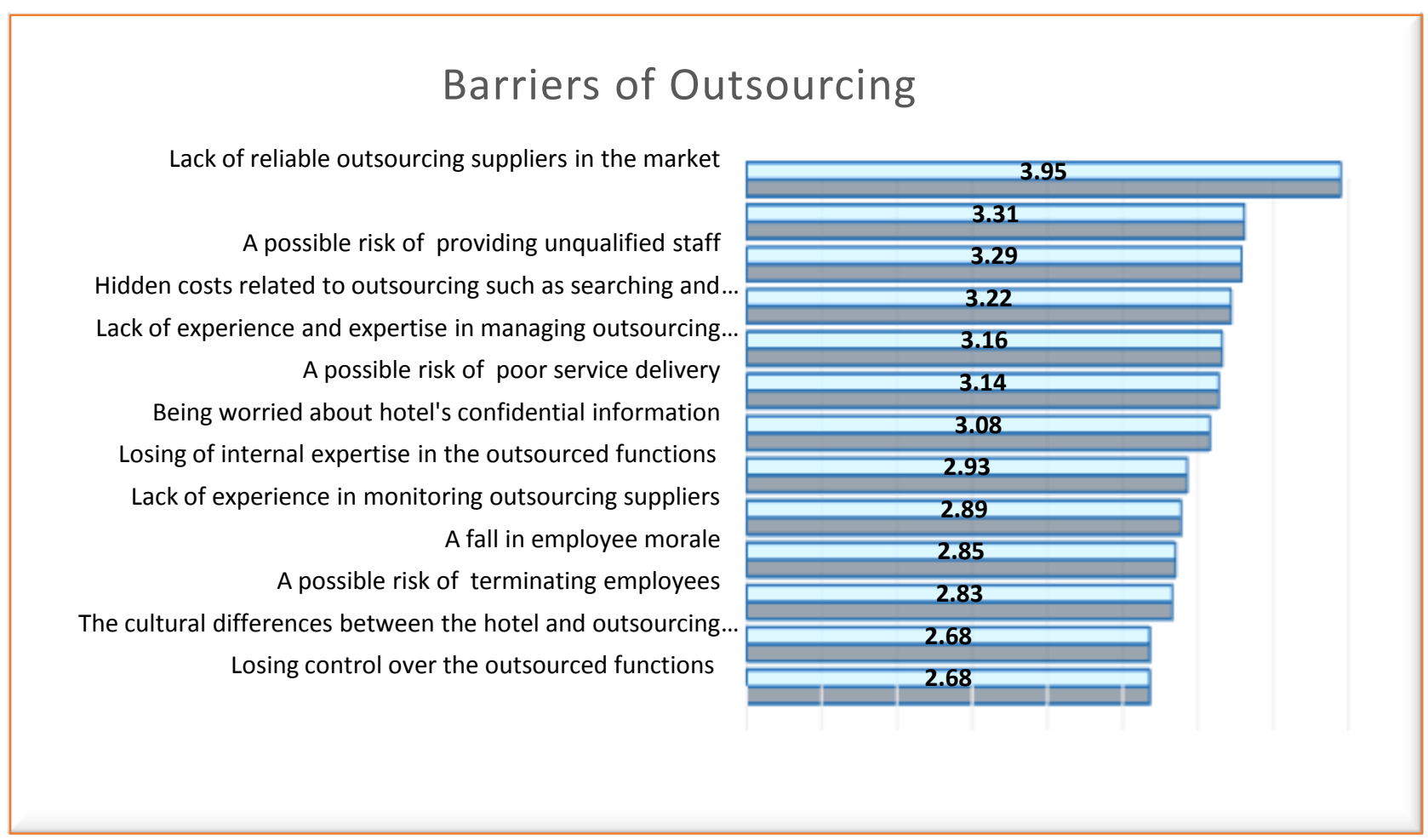

Figure 2: Barriers of Outsourcing in the Egyptian Hotel Market

Hidden costs related to outsourcing such as searching and negotiating costs is another factor inhibiting hotel managers from outsourcing. According to Power et al. (2006), there are two major types of cost: direct and indirect. Direct costs are usually very tangible and easy to measure, including the cost of conducting the outsourced service. Indirect costs are the expenses that the organization has to bear, but are difficult to measure. These include items such as legal fees to develop contracts, employee assistance and displacement fees owing to job reassignment or terminations and communications expenses. The literature reviewed highlighted two types of hidden costs related to outsourcing; cost of setting up the contract (including the costs of resolving disputes and discrepancies, meeting with the vendors, negotiations, etc.) which sometimes take a lot of time, and costs of a supplier failing and contracting a new one (Power et al., 2006).

Lack of experience and expertise in managing outsourcing contracts, although it had not been discussed as a barrier for outsourcing in the consulted literature, this statement is first used in this study to check how managers evaluate their capabilities concerning managing outsourcing contracts. Surprisingly more than half of respondent managers admit that there is a lack of expertise in managing outsourcing contracts. The contract is the legal document that binds the vendor and client and guides how they are going to work together sometimes on a daily basis throughout the life of the contract. A hotel general manager referred to the significance of involving a lawyer to check and revise the 
contract items before signing. According to Power et al. (2006), outsourcing contracts can range in depth, detail, form, and duration. However, good contracts are clear, concise, and complete and have well-defined statements on how the client and vendor organizations will meet each other's business outcomes and expectations.

A possible risk of poor service delivery is another barrier inhabiting hotel outsourcing, where many respondents highlighted this point. Poor quality of supply can manifest itself in many ways based on the type of service outsourced. Pest control, for instance, could suffer from using low quality products that may cause harm and health related risks. In terms of maintenance outsourcing, hotels also suffered from the delay of technical support from the manufacturing company. This sheds light on the importance of supplier selection as a determinant factor in avoiding many outsourcing risks.

The need for confidentiality and being worried about hotel's confidential information in certain areas of a hotel's operations is also regarded as a prohibiting factor for outsourcing. Wan and Su (2010) determined certain aspects of hotel operations that are considered commercial secrets, and therefore, cannot be outsourced. These include survey reports, payroll systems, employee profiles, labor cost and purchasing specifications as well as marketing and promotion plans. In supportive view, Promsivapallop (2009) indicated that confidential information serves as a hindrance to outsourcing the HR where there are salary structures, and employees' profiles. Many respondents, however, did not consider this issue as a barrier for outsourcing this may be because hotels are engaged in forms of non-core activity outsourcing.

Concerning losing of internal expertise in the outsourced functions, it is widely noted that outsourcing is risky because if a supplier's performance is unacceptable, it is difficult to bring the activity back in-house due to the loss of internal skill base. Despite being a common cited barrier for outsourcing in the literature (Lamminmaki, 2003; EspinoRodriguez \& Padron-Robaina, 2005; Hiamey \& Amenumey, 2013) only one third of respondents agreed with this statement while, two thirds of hotels were not concerned about losing internal capabilities because of outsourcing. This is in line with Domberger (1998) who argued that loss of in house skills through outsourcing is not a concern if skills can be competitively obtained in the market and if there are many potential suppliers.

As for lack of experience in monitoring outsourcing suppliers, the managers' views towards this statement as a barrier of outsourcing were mixed. Some respondents highlighted the difficulty of monitoring and measuring the providers' performance as a barrier for outsourcing; in addition to being uncertain about the expected service level and its compliance with accepted quality standards. Therefore, they decided to manage their hotel functions in house. This is in line with the view of Power et al. (2006) who claimed that one of the most critical tasks in an outsourcing engagement is ensuring that the work that has been undertaken gets done as agreed.

As for the fall in employee morale, only $18.7 \%$ of respondent managers considered as a barrier for outsourcing. This contradicts with Elmuti and Kathawala (2000) as well as Belcourt (2006), who cited employee morale among the primary risks in outsourcing. Stroh and Treehuboff (2003) also referred that outsourcing endeavors could have a profound impact on employee morale either positively or negatively.

Furthermore, a possible risk of terminating employees was not perceived as a solid barrier for outsourcing from managers' viewpoint. In explaining how they manage this issue, a respondent manager claimed that the hotel gave the employees who have been 
working in security department the choice to be transferred to the outsourced company or transferred to another department based on the possibility. This practice is in line with Belcourt (2006), who described outsourcing as work that is traditionally done internally is shifted to an external provider, and the employees of the original organization are often transferred to the service provider. Previous studies specified three options for the employees who previously carried out the outsourced activity: either they are transferred to the outsourcing company, transferred internally to other functions or they are laid off (Belcourt, 2006; Kakabadse \& Kakabadse, 2000). In a distinctive view, Sriwongwanna (2009) found that when the organization introduced outsourcing processes, it created different career opportunities for employees.

Unlike previous studies and researches, losing control over the outsourced functions was among the least cited barriers by respondent managers. This disagrees with Raiborn et al. (2009), Hiamey and Amenumey (2013), and Lau and Zhang (2006) where loss of control was a common reason for hotels not venturing into outsourcing. According to Hamzah et al. (2010), supported by Sani et al. (2013), hotels are concerned about losing control over the outsourced functions because it is more difficult to manage outside service providers than managing one's own employees.

The majority of managers also did not perceive the cultural differences between the hotel and outsourcing supplier as a barrier that hinder outsourcing in hotels. Despite being different from previous researches and studies this issue also sounds rationalized, because cultural conflicts can arise when workers are from different countries with different cultures, sometimes conflicts arise when the outsourced staff are speaking different language or from different locations. This is consistent with Power et al. (2006: 12 ), who stated that one of the clear benefits of outsourcing to an onshore location is the fact that there are fewer cultural issues.

Overall, not all the aforementioned risks are inevitable. Nor are they necessarily sufficient to outweigh the real economic, administrative, and organizational benefits of outsourcing. However, hotels have to find the most effective way of limiting the vendor opportunism, maintaining control, and obtaining the long-term value. In addition, Quinn and Hilmer (1994) and Power et al. (2006) highlighted that both outsourcing decision and carrying on the activities in-house have risks. It should also be noted that many of the discussed risks are not related to "outsourcing" but the way it is applied. Therefore, many of these risks can be avoided if the hotel selects the right supplier.

\section{Conclusion and Recommendations}

The main objective of this study was to explore the use of outsourcing among hotels in Egypt by looking at functions outsourced, reasons for outsourcing, as well as the challenges faced by outsourcing hotels. This study shows outsourcing as a common tool used in the Egyptian hotel market in both city and resort style hotels. Outsourcing made a paradigm shift in the way hotel functions are conducted. Most of hotel activities that had been performed in-house are no longer conducted in this way since they are becoming more available and affordable in the market for hotels to outsource. Used correctly, outsourcing can indeed deliver benefits such as cost reductions, focusing on core hotel activities, improved quality, and competitive advantages. The future of outsourcing will witness an increase in the outsourcing of non-core activities. The outcomes of this study, 
when correlated to the review of literature, raised major recommendations that have to be directed to towards two groups including hotel managers, and government bodies.

- Non-outsourcing hotels should benchmark the successful outsourcing practices performed by outsourcing hotels and start to outsource some of their hotel functions to seize the benefits of outsourcing.

- Every hotel should identify its core and peripheral activities and outsource only the non-core activities, which have a supporting nature. As well as areas that cause problems under the hotel management and there is someone else outside who can do it better.

- Independent hotels can outsource customer satisfaction appraisal to an outside third party or even obtain"software" that handles the guests' reviews without employees' intervention to assure the accurateness of guest comments and reviews .Employee satisfaction surveys can also be outsourced to facilitate the collection of employees' reviews regarding their work environment .

- The Ministry of Tourism can provide training sessions on "how to effectively apply the outsourcing strategy" as a syllabus on their hotel training programs .

- Hospitality researchers, as well as industry professionals can corporate to develop a handbook (Hospitality Industry Specific Guidelines for Outsourcing) that provides practical guidance for outsourcing different hotel activities.

- Hospitality and Tourism Faculties and Institutions should start to play the role of employment agencies, through establishing a web based recruitment center (WBRC), which allows faculty graduates to share their $\mathrm{CVs}$, and allows hotel managers to recruit and hire easily.

Some limitations encountered the present research. This study was interested in investigating the nature of applying outsourcing in the Egyptian hotel market, by answering questions of "what" and "why". However, questions of "how", (i.e. how the outsourcing strategy is implemented), had not been tackled in this study. Moreover, the study was confined to four and five star hotels. Despite being justified, the study's findings are therefore not generalizable to lower quality or smaller hotels. Further, it would be beneficial also to broad the scope and tackle areas of research from suppliers' or outsourcers' side like ; the quality of service providers and satisfaction of hotels with available companies, as well as, the human resource issues and training needs of the outsourcers.

\section{References}

- Barthélemy, J. (2003) 'The seven deadly sins of outsourcing', The Academy of Management Executive, 17(2), 87-100.

- Baytok, A., Soybali, H., and Zorlu, O. (2013) 'Outsourcing in thermal hotel enterprises: the case of Turkey', Business Management Dynamics, 3(5), 1-14.

- Belcourt, M. (2006) 'Outsourcing the benefits and the risks', Human Resource Management Review, 16, 269279.

- Bolat, T., and Yilmaz, O. (2009) 'The relationship between outsourcing and organizational performance: Is it myth or reality for the hotel sector', International Journal of contemporary Hospitality Management, 21(1) 723.

- Burgess, C. (2007) 'Is there a future for hotel financial controllers? ', Hospitality Management, 26, 161-174. 
- Campbell, J. D. (1995) 'Outsourcing in maintenance management: A valid alternative to self-provision', Journal of Quality in Maintenance Engineering, 1(3), 18-24.

- Cooper, A. (2007) 'To outsource or not to outsource', Supply Management, 12(10), 22-26.

- Corbett, M. F. (2004) 'Outsourcing revolution: Why it makes sense and how to do it right', Dearborn Trade. Chicago: A Kaplan Professional Company.

- Creswell, J. W. (2002) Educational research: Planning, conducting, and evaluating quantitative and qualitative approaches to research, Upper Saddle River, NJ: Merrrill/Pearson Education.

- Domberger, S. (1998) The Contracting Organization: A strategic guide to outsourcing, Oxford: Oxford University Press.

- Domberger, S., Hall, C., and Li, E. A. L. (1994) 'The determinants of quality in competitively tendered contracts', Working Paper, Graduate School of Business, University of Sydney, Australia.

- Donada, C., and Nogatchewsky, G. (2009) 'Emotions in outsourcing: An empirical study in the hotel industry', International Journal of Hospitality Management, 28, 367-373.

- Dorasamy, M., Marimuthu, M., Jayabalan, J., Raman, M., and Kaliannan, M. (2010) 'Critical factors in outsourcing of accounting functions in Malaysian small medium-sized enterprises (SMEs)', Kajian Malaysia, $28(2), 39-46$.

- Ecerkale, K., and Kovanc1, A. (2005) 'Outsourcing in Human Resources', Journal of Aviation and Space Technologies, 2(2), 69-75.

- Elmuti, D. (2003) 'The Perceived impact of outsourcing on organizational performance', American Journal of Business, 18(2), 33 - 41.

- Embleton, P. R., and Wright, P. C. (1998) 'A practical guide to successful outsourcing', Empowerment in Organizations, 6(3), 94-106.

- Espino-Rodríguez and Rodríguez-Díaz (2008) 'What type of outsourcing relationship should hotels maintain? A model based on internal and relational strategic value', Advances in Hospitality and Leisure, 4, 213-227: doi:10.1016/S1745-3542(08)00010-6.

- Espino-Rodriguez, T. F., and Gil-Padilla, A. M. (2005) 'Determinants of information systems outsourcing in hotels from the resource-based view: An empirical study', International Journal of Tourism Research, 7, 35-47.

- Espino-Rodriguez, T. F., and Padron-Robaina, V. (2004) 'Outsourcing and its impact on operational objectives and performance: A study of hotels in the Canary Island', International Journal of Hospitality Management, 23, 287-306.

- Espino-Rodriguez, T. F., and Padron-Robaina, V. (2005) 'A resource-based view of outsourcing and its implications for organizational performance in the hotel sector', Tourism Management, 26, $707-721$.

- Espino-Rodriguez, T. F., and Padron-Robaina, V. (2006) 'A review of the outsourcing from the resource-based view of the firm', International Journal of Management Reviews, 8(1), 49-70.

- Espino-Rodriguez, T. F., Lai, P. C. and Baum, T. (2008) 'Asset specificity in make or buy decisions for service operations', International Journal of Service Industry Management, 19(1), 111 - 133.

- Galahitiyawe, N., and Musa, G. (2011) 'The measuring framework of outsourcing success: An exchange perspective', Annual Summit on Business and Entrepreneurial Studies (ASBES), Proceeding, 21_35, Faculty of Business and Accountancy, University of Malaya, Kuala Lumpur.

- Ghodeswar, B., and Vaidyanathan, J. (2008) 'Business process outsourcing: an approach to gain access to world-class capabilities', Business Process Management Journal, 14(1), 23-38.

- Glagola, J. R. (2000) 'Outsourcing: Opportunities and challenges for corporate competitiveness', Journal of Corporate Real Estate, 2(1), $14-49$.

- Gonzales, R., Llopis, J., and Gasco, J. (2011) 'What do we know about outsourcing in hotels?', The Service Industries Journal, 31(10), 1669-1682.

- Grauman, K., and Paul, E. (2005) 'Top 10 mistakes when outsourcing benefits', Employee Benefit News,1.

- Greer. C. R., Youngblood, S. A., and Gray, D. A. (1999) 'Human resource management outsourcing: The make or buy decision', Academy of Management Executive, 13(3), 85-96.

- Grossman, G. M., and Helpman, E. (2005) 'Outsourcing in a global economy', The Review of Economic Studies, 72, 135-159: Doi: 0034-6527/05/00070135\$02.00. 
- Hamzah, N., Aman, A., Maelah, R., Auzair, S. M., and Amiruddin, R. (2010) 'Outsourcing decision process: A case study of a Malaysian firm', African Journal of Business Management, 4(15), 3307-3314.

- Hansen, F. (2009) 'Currents in compensation and benefits', Compensation and Benefits Review, 41(1), 5-24.

- Hemmington, N., and King, C. (2000) 'Key dimensions of outsourcing hotel food and beverage services', International Journal of Contemporary Hospitality Management, 12(4), 256-261.

- Heywood, J. B. (2001) The outsourcing dilemma: The search for competitiveness. Great Britain: Pearson Education Limited.

- Hiamey, S. E. (2012) Outsourcing of hotel services in the Accra Metropolis of Ghana (Unpublished MPhil Thesis), Department of Hospitality and Tourism Management, University of Cape Coast, Cape Coast, Ghana.

- Hiamey, S. E., and Amenumey, E. K. (2013) 'Exploring service outsourcing in 3-5 Star hotels in the Accra Metropolis of Ghana', Tourism Management Perspectives, 8, 9-17.

- Holcomb, T. R., and Hitt, M. A. (2007) 'Toward a model of strategic outsourcing', Journal of Operations Management, 25, 464-481.

- Hottman, R., and Adams, J. (1996) 'Go with what you know: outsourcing? Reality or myth?', Bottomline, 11(7), 22-3.

- Jennings, D. (1997) 'Strategic guidelines for outsourcing decisions', Strategic Change 6, 85-96.

- Kakabadse, N., and Kakabadse A. (2000) 'Critical review - outsourcing a paradigm shift', Journal of management development, 19(8), 670-728.

- Kern, T., and Willcocks, L. P. (2002) 'Exploring relationship in information technology outsourcing: The interaction approach', European Journal of Information Systems, 11(1), 3-19.

- Kim, B. M. (2006) Convention services manager's perception of the strategic outsourcing of convention services (Master's Thesis), University of Nevada, Las Vegas.

- Knox, A. (2010) 'Lost in translation: An analysis of temporary work agency employment in hotels', Work Employment Society, 24, 449-467.

- Kremic, T., Tukel, O. I., and Rom, W. O. (2006) 'Outsourcing decision support: A survey of benefits, risks, and decision factors. Supply Chain Management', An International Journal, 11(6), 467-482.

- Kumar, S., and Eickhoff, J. (2005) 'Outsourcing: When and how should it be made', Information knowledge systems management, 5(5), 245-259.

- Lai, P. C. (2007) 'Outsourcing hotel service operations: The case of Taiwan hotels', Proceeding of International Conference on Business and Information, 11-13 July. Tokyo, Japan.

- Lam, T. and Han, M. X. J. (2005) 'A Study of outsourcing strategy: A case involving the hotel industry in Shanghai, China', International Journal of Hospitality Management, 24(1), 41 - 56.

- Lamminmaki, D. (2003) Outsourcing in the hotel industry: A management accounting perspective (PhD dissertation), Griffith University, Gold Coast, Australia.

- Lamminmaki, D. (2005) 'Why do hotels outsource? An investigation using asset specificity', International Journal of Contemporary Hospitality Managment, 17(6), 516-528.

- Lamminmaki, D. (2006) Outsourcing in the hotel industry: A management accounting perspective. In: Harris, P., Mongiello, M. (Eds.), Accounting and Financial Management: Developments in the International Hospitality Industry. Butterworth-Heinemann.

- Lamminmaki, D. (2007) 'Outsourcing in Australian hotels: A transaction cost economics perspective', Journal of Hospitality and Tourism Research, 31 (1), 73-110.

- Lamminmaki, D. (2008) 'Accounting and the management of outsourcing: An empirical study in the hotel industry', Management Accounting Research, 19, 163-181.

- Lamminmaki, D. (2009) 'An investigation of the role played by frequency and uncertainty in hotel outsourcing decisions', International Journal of Services Technology and Management, 11, 182-201.

- Lamminmaki, D. (2011) 'An examination of factors motivating hotel outsourcing', International Journal of Hospitality Management, 30, 963-973.

- Lau, K. H., and Zhang, J. (2006) 'Drivers and obstacles of outsourcing practices in China', International Journal of Physical Distribution and Logistics Management, 36(10), 76-792.

- Leavitt, H. J., Pondy, L. R., and Boje, D. M. (1989) Reading in managerial psychology, (5 ${ }^{\text {th }}$ edition). Chicago: University of Chicago Press.

- Lee, S. (2008) 'Outsourcing Innovation in a Durable good monopoly', American Economist, 52(1), 96 - 107. 
- Linder, J. C., Cole, M. I., and Jacobson, A. L. (2002) 'Business transformation through outsourcing', Strategy and Leadership, 30 (4), 23-28.

- Loh, L., and Venkatraman, N. (1992) 'Determinants of information technology outsourcing: A cross-sectional analysis', Journal of Management Information Systems, 9(1), 7-24.

- Maelah, R., Aman, A., Hamzah, N., Amiruddin, R., and Auzair, S. M. (2010) 'Accounting outsourcings turn back: Process and issues. Strategic outsourcing', An International Journal, 3(3), 226-245.

- Maiga, A. S., and Jacobs, F. A. (2004) 'The association between benchmarking and organizational performance: An empirical investigation', Managerial Finance, 30(8), 13-33.

- McIvor, R. (2005) The outsourcing process: Strategies for evaluation and management. New York, NY: Cambridge University Press.

- McIvor, R. (2009) 'How the transaction cost and resource-based theories of the firm inform outsourcing evaluation', Journal of Operations Management, 27, 45-63.

- Merrifield, D. B. (2006) 'Make outsourcing a core competency', Research Technology Management, 49(3), 10.

- Nayebzadeh, S., Sharifabadi, A. M. and Golshan, M. (2013) 'The role of accounting department in outsourcing decision-making; case study: Yazd textile industry', Journal of Basic and Applied Scientific Research, 3(3), 1017-1024.

- Oates, D. (1998) Outsourcing and the virtual organization: The incredible shrinking company. London: Century Ltd.

- Ono, Y. (2007) Outsourcing business services, the scope of local markets, and agglomeration economies (Thesis), Retrieved from July 31, 2015ftp://ftp2.census.gov/ces/wp/2001/CES-WP-01-15.pdf

- Ordoobadi, S. (2009) Development of a decision model for supplier selection. University of MassachusettsDartmouth.

- Paraskevas, A., and Buhalis, D. (2002) 'Outsourcing IT for small hotels: The opportunities and challenges of using application service providers', Cornell Hotel and Restaurant Quarterly, 43(2), 27-39.

- Polit, D. F., Beck, C. T., and Hungler, B. P. (2001) Essentials of nursing research: Methods, appraisal and utilization $\left(5^{\text {th }}\right.$ ed.). Philadelphia: Lippincott Williams \& Wiilkins.

- Potkány, M. (2008) 'Personnel outsourcing processes', E+M Ekonomie a Management, 4, 53 - 62.

- Power, M. J., Desouza, K. C., and Bonifazi, C. (2006) The outsourcing handbook: how to implement a successful outsourcing process. London and Philadelphia published in Great Britain and the United States.

- Promsivapallop, P., (2009) A critical evaluation of transaction cost economics applied to outsourcing in the hotel industry in Thailand (PhD Thesis), University of Surrey, School of Management, Thailand.

- Promsivapallop, P., Jones, P. and Roper, A. (2015) 'Factors influencing hotel outsourcing decisions in Thailand: Modifications to the transaction cost economics approach', Journal of Hospitality \& Tourism Research, 39(1), 32-56: DOI: $10.1177 / 1096348012461546$.

- Quinn, J. B., and Hilmer, F. G. (1994) 'Strategic outsourcing', Sloan Management Review, 35 (4), 43-55.

- Raiborn, C. A., Butler, J. B., and Massoud, M. F. (2009) 'Outsourcing of support functions: Identifying and managing the good, the bad and the ugly', Business Horizons, 52, 347-356.

- Rodrigues, T. F., Lai, P.C., and Baum, T. (2008) 'Asset specificity in make or buy decisions for service operations-An empirical application in the Scottish hotel sector', International Journal of Service Industry Management, 19(1), 111-133.

- Rowe, M. (1993) 'If you can't beat me, join me', Lodging Hospitality, 49(13), 57-69.

- Sani, A., Dezdar, S., and Ainin, S. (2013) 'Outsourcing patterns among Malaysian hotels', International Journal of Business and Social Science, 4(9), 133_144.

- Shirazi, A. M., and Aslanzadeh. A. (2011) Assessing hotel outsourcing activities in Arya hotel chains (MPhil Thesis), Department of Business Administration, Technology and Social Sciences. University of Technology, Luleå. Retrieved from https://pure.ltu.se/ws/files/36591724/LTU-EX-2012-36549599.pdf

- Sirec, K., Rebernik M., and Hojnik, B. B. (2012) 'Managing tacit knowledge in strategic outsourcing', University of Maribor, Faculty of Economics and Business Slovenia.

- Smith, A. (2012). The Pros and Cons of Outsourcing (Master's Thesis). University of Nevada, Las Vegas. 
- Soltani, E., and Wilkinson, A. (2010) 'What is happening to flexible workers in the supply chain partnerships between hotel housekeeping departments and their partner employment agencies?', International Journal of Hospitality Management, 29 (1), 108-119.

- Song, L. (2008) 'An analysis on Chinese hotel enterprises' outsourcing strategic modes and corresponding development conception', International Journal of Business and Management, 3(3), 76-81.

- Sriwongwanna, J. (2009) Understanding the impact of outsourcing human resource activities on employee attitudes and behaviors (PhD Thesis), Murdoch University. URI: http://researchrepository.murdoch.edu.au/id/eprint/2970

- Stroh, L. K., and Treehuboff, D. (2003) 'Outsourcing HR functions: When and when not to go outside', Journal of Leadership and Organizational Studies, 10(1), 19-28.

- Wan, C. H., and Su, A. Y. L. (2010) 'Exploring the factors affecting hotel outsourcing in Taiwan', Pacific Journal of Tourism Research, 15(1), 95-107.

- Yildiz, S. and Demirel, Z. H. (2014) 'The benefits, risks, and effects on performance of the outsourcing: A comparative study of seasonal and permanent hotels', Procedia-Social and Behavioral Sciences, 109, $514-$ 521.

- Zhu, Z., Hsu, K., and Lillie, J. (2001) 'Outsourcing a strategic move: The process and the ingredients for success', Management Decision, 39(2). Retrieved November 07, 2013 from: http://www.businessdictionary.com/ http://www.entrepreneur.com. 